\title{
Representações de si e sentimento moral: uma pesquisa sobre fracasso escolar
}

\author{
The representations of self and the moral feeling: a research about school \\ failure
}

\section{Representaciones de sí y el sentimiento moral: una investigación sobre el fracaso escolar}

\author{
Kelly Jessie Queiroz Penafiel' \\ Vanessa Aparecida Alves de Lima" \\ 'Universidade Federal de Rondônia, Câmpus de Vilhena, Rondônia - Brasil. E-mail: \\ kellyjessierm@gmail.com \\ "Universidade Federal de Rondônia, Câmpus de Porto Velho, Rondônia - Brasil. E-mail: \\ limavanessa@uol.com.br
}

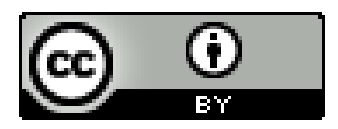

Educação: teoria e prática, Rio Claro, SP, Brasil - eISSN: 1981-8106

Está licenciada sob Licença Creative Common

\section{Resumo}

Neste trabalho, discutem-se as representações de si e o sentimento de vergonha frente às situações de fracasso escolar vivenciadas por adolescentes que frequentam o nono ano do ensino fundamental. A pesquisa foi realizada por meio de entrevista clínica com 49 adolescentes, meninos e meninas, em seis escolas públicas do município de Rolim de Moura, Rondônia, com objetivo de compreender aspectos relevantes das representações que fazem de si diante do fracasso escolar, tendo como marco teórico os estudos de Piaget sobre o desenvolvimento moral infantil e as pesquisas contemporâneas na perspectiva da Psicologia Moral. Os resultados apontam para o fato de que os sujeitos sentem-se culpados pelo fracasso, mas, em alguns casos, não sentem vergonha; em outros, apesar de sentirem, a vergonha não implica em representação negativa de si. Por fim, constatamos que os dados de nossa pesquisa endossam as ideias de que a busca de representações positivas de si é uma das motivações básicas da conduta humana. 
Palavras-chave: Psicologia Moral. Representações de si. Vergonha. Fracasso escolar.

\begin{abstract}
In this paper is discussed the representations of self and the feeling of shame before the school failures situations experienced for teenagers attending the ninth year of elementary school. We conducted this survey by a clinical interview with 49 teenagers, boys, and girls, in six public schools in the municipality of Rolim de Moura, Rondônia, to understand relevant aspects of the representations that make themselves before their failure in school. This research has as a theoretical landmark, the studies of Piaget on children's moral development, the contemporary surveys from the perspective of Moral Psychology. The results indicate that subjects feel guilty for the failure, but in some cases, they do not feel ashamed and, in others cases, despite the fact that they believe it, it does not imply a negative representation of self. Finally, we noted that the data from our surveys endorse the ideas that the search of positive representations of self is one of the fundamental motivations of human behavior.
\end{abstract}

Keywords: Moral Psychology. Representations of self. Shame. School Failure.

\title{
Resumen
}

En este trabajo se discuten las representaciones de si mismo e el sentimiento de vergüenza frente a las situaciones de fracaso escolar vivenciadas por los adolescentes que cursan el noveno grado de enseñanza primaria. La investigación se llevó a cabo mediante entrevista clínica con 49 adolescentes, niños y niñas en escuelas públicas del municipio Rolim de Moura, Rondonia, con el fin de comprender los aspectos relevantes de las representaciones que hacen de si mismo delante del fracaso escolar, teniendo como marco teórico los estúdios de Piaget sobre el desenvolvimiento moral infantil, las investigaciones contemporáneas en la perspectiva de la Psicología Moral. Los resultados apuntan para el hecho de que los sujetos se sienten cupables por el fracaso, pero, en algunos casos, no sienten vergüenza. En cambio, hay aquellos que, aunque se sienten avergonzados, la vergüenza no implica en la representación negativa de si mismo. Por último, constatamos que los datos de nuestra investigación respaldan las ideas de que la búsqueda de representaciones positivas de si mismo es una de las motivaciones básicas de conducta humana.

Palabras clave: Psicología Moral. Representaciones de si mismo. Vergüenza. Fracaso escolar.

\section{Introdução}


Em nossa cultura, o espaço da escola na vida das pessoas possui natureza definida e muitos concordam com sua importância e necessidade na busca de "uma vida melhor". Mais do que um aluno, o sujeito que está na escola é um ser social, afetivo e moral, determinado por relações sociais e históricas que marcam suas vivências dentro e fora do universo escolar; condição que a escola, na maioria das vezes, ignora.

Neste trabalho, compreendemos o fracasso na escola não só como repetência, mas como todo sentimento de inadequação e toda situação que leva um sujeito a ser excluído. No cotidiano escolar, os alunos falam sobre suas vivências, suas histórias de vida e revelam um sentimento ambivalente em relação à escola, que se constitui como objeto de desejo e medo.

Nesse aspecto, acreditamos que as contribuições da Psicologia Moral são de grande ajuda para compreender as interfaces desse fenômeno chamado fracasso escolar. A moral está associada aos valores humanos e, diante disso, é possível estabelecer relações entre a moralidade e as relações de convivência do espaço escolar. Por isso, ao ouvir os adolescentes, este trabalho contribui para essa discussão, ampliando os estudos sobre o tema na perspectiva da moralidade.

As escolas são espaços onde os alunos experimentam diversos tipos de interações nelas circulam culturas, conhecimentos, saberes e tradições culturais. Reconhecer, os alunos, como atores importantes nesse contexto e procurar compreender suas concepções acerca da instituição escolar que frequentam é, ao mesmo tempo, aprender sobre eles e sobre a escola.

Diante das considerações apresentadas, compreendemos que há relevância em priorizar a reflexão sobre a relação entre adolescência e escolarização, ressaltando a necessidade de contribuir para o questionamento de estereótipos endossados por teorias que rotulam e silenciam o sujeito.

\section{Representações de si e o sentimento de vergonha}

O conceito de vergonha pode apresentar um campo de significados bastante amplo. Para La Taille (2007), trata-se de um desconforto psíquico decorrente da exposição e do juízo negativo. Na vergonha de exposição, está presente o fato de o sujeito se perceber como objeto do olhar alheio. Por outro lado, a vergonha que o autor denomina "judicativa" pressupõe um juízo negativo. É quando a vergonha encontra sua tradução mais frequente em sentimentos de rebaixamento, desonra e humilhação.

A vergonha configura-se no encontro de outros dois sentimentos: a inferioridade e a exposição. A inferioridade manifesta-se de várias maneiras, aqui consideradas duas como relevantes: o rebaixamento de si e a humilhação, causados por opiniões negativas que os outros têm de sua imagem projetada e pela indignidade sentida a partir de uma sanção negativa imposta pelo sujeito a si mesmo (HARKOT-DE-LA-TAILLE, 1996). 
Podemos considerar que os julgamentos alheios podem despertar o sentimento de vergonha ou mesmo ampliar sua força. Contudo, segundo La Taille (2002), a condição necessária para que ocorra é o juízo negativo de quem a experimenta. O sujeito que sente vergonha julga a si próprio negativamente.

Uma vez que a vergonha pressupõe um autojuízo negativo, cabe destacar que o que está em jogo é o Eu. Mesmo que a vergonha possa ser desencadeada por ações, é o Eu que continua em destaque, o Eu que é desvalorizado. Falar num Eu desvalorizado remete-nos às Representações de si (LA TAILLE, 2002).

A expressão "Representações de si” foi idealizada por Roger Perron, segundo quem o Eu é sempre assimilado como valor. As imagens de si são construídas como conjunto de valores, isto é, quando uma pessoa pensa em si, constrói imagens associadas ao bem ou ao mal, ao desejável ou ao indesejável, ao certo ou ao errado: “[...] mesmo as formas aparentemente mais objetivas de se representar, como ser mulher ou homem, criança ou adulto, [...] estão prenhes de valor." (LA TAILLE, 2002, p. 61). Assim, conhecer-se implica julgar-se.

La Taille (2010) entende o Eu como um conjunto de representações de si, imagens que a pessoa faz de si mesma, não importando se tais representações correspondam, de fato, ao que a pessoa realmente é ou como é vista pelos outros, mas ao que ela julga ser. Essa representação não é inata, mas construída, e começa a ser esboçada com o início da construção da consciência de si. Pode-se dizer que a "[...] tomada de consciência e ser percebido por outrem são contemporâneos no desenvolvimento da criança" (LA TAILLE, 2002, p.58).

Se admitirmos, conforme La Taille (2002), que as representações de si estão sempre situadas em planos valorativos e que os indivíduos estão sempre em busca de representações de si positivas, cabe questionar se as pessoas têm uma tendência a procurar certos valores em detrimento de outros.

No conjunto das representações de si, certos valores podem ser centrais e outros periféricos. Uma pessoa pode se ver como bonita, isto é, ter de si a imagem de que é bonita fisicamente - mesmo que não o seja. Pois, conforme defende La Taille (2002), as representações de si estão na dimensão simbólica e não real, podendo uma percepção física positiva ter mais valor do que se ver como honesta ou justa. Nesse caso, a representação de si relacionada à beleza é central e a relacionada à moral é periférica.

Os valores que ocupam a parte central das representações de si têm maior força motivacional (LA TAILLE, 2002). A pessoa para quem a beleza física é um valor central na sua identidade investirá maiores esforços na conservação ou no incremento dessa beleza do que na tentativa de ser honesta ou justa, sendo esses dois últimos valores periféricos. Em consequência, sentirá mais vergonha de não se ver como bonita do que de não se ver como honesta e/ou justa. 
Se tomarmos a construção das representações como valorativas e nos lembrarmos de que a aprendizagem dos conteúdos escolares é socialmente valorizada, podemos considerar que essa aprendizagem integra as expectativas pessoais. Além disso, os resultados do desempenho escolar podem ser compreendidos como sucessos e fracassos objetivamente constatados. Sendo assim, o desempenho escolar pode ser um dos fatores que influenciam nas representações feitas pelos alunos.

Embora o fracasso em determinada atividade costume vir acompanhado de juízos negativos de outras pessoas, “[...] a frustração de não ter tido êxito pode desencadear uma autoavaliação negativa" (LA TAILLE, 2002, p. 69). Ainda que não sejam causas exclusivas da construção das representações de si, os olhares e juízos alheios desempenham um papel fundamental nesse processo.

Concordamos com La Taille (2009a) quando afirma que a escola é uma instituição incontornável para a educação moral, uma vez que representa a transição do espaço privado (família) para o espaço público (sociedade). As dimensões morais necessárias para se inserir neste último podem ser trabalhadas em sala de aula. Em escolas que sejam verdadeiras instituições justas, as chances de que os alunos desenvolvam-se como sujeitos autônomos, inspirados pelo respeito de si, são maiores.

\section{A Pesquisa}

Objetivamos, nesta pesquisa, compreender como a Representação de si se relaciona com o sentimento de vergonha e a experiência de fracasso escolar, e relacionar a forma como adolescentes com idade entre 13 e 16 anos fazem corresponder o fracasso escolar ao sentimento de vergonha.

A pesquisa foi desenvolvida com alunos de escolas públicas no município de Rolim de Moura, Rondônia. Neste, a rede estadual de ensino é composta por dez escolas que oferecem Ensino Fundamental e Médio. Dessas, nove atendem aos anos finais do Ensino Fundamental, público com o qual trabalhamos. A investigação foi realizada em seis dessas escolas, onde estavam matriculados, no ano de 2011, 5.505 alunos. Desse total, 392 (7,13\%) cursavam o 9. ${ }^{\circ}$ ano do Ensino Fundamental, distribuídos em 14 turmas, que foram todas convidadas a participar da pesquisa. Voluntariamente, 158 alunos levaram para casa o Termo de Consentimento Livre e Esclarecido. Tivemos um retorno de $31 \%$ dos termos devidamente assinados por pais e/ou responsáveis, totalizando 49 sujeitos entrevistados - 16 meninos e 33 meninas.

A entrevista que utilizamos teve como base a técnica da entrevista clínica piagetiana. Conforme explicam Queiroz e Lima (2011), o procedimento consiste em uma conversa aberta com o sujeito, na qual se procura seguir suas ideias e explicações sobre um determinado tema. 
Buscamos, então, adotar uma postura dialógica, procurando entender o ponto de vista do adolescente sobre sua representação de fracasso escolar, a representação de si e de outrem diante dessa experiência e o sentimento de vergonha envolvido (ou não) na situação. Dessa forma, apresentamos a seguinte frase bruta: "Ana/Pedro de 14 anos fracassou na escola" ". Em seguida, pedimos ao sujeito que nos dissesse o que significava para ele/ela fracassar na escola.

\section{Fracasso Escolar e o sentimento de vergonha}

Um dos maiores desafios enfrentados pela educação pública no Brasil é garantir a todos uma educação de qualidade capaz de favorecer a emancipação intelectual. Sabe-se que essa não tem sido uma tarefa bem sucedida e a escola brasileira não tem cumprido com sua função primordial de garantir ensino de qualidade.

Em vez de ampliar a compreensão crítica da realidade, a escola mantém uma prática seletiva, discrimina alunos, classificando-os em "aptos" e "inaptos", excluindo e culpabilizando-os pelo fracasso escolar. Aqueles que não se adaptam aos padrões préestabelecidos são tidos como problemas. A psicologia e a pedagogia, naquilo que Bock (2003) chama de "cumplicidade ideológica", contribuem para essa exclusão quando criam critérios que rotulam os alunos.

Compreendemos que o fracasso escolar não se reduz a repetência e evasão, mas a todo sentimento de inadequação e toda situação que leva um sujeito a ser excluído e estigmatizado. Procurando compreender o ponto de vista dos sujeitos sobre o tema, pedimos que nos dissessem o que significa para eles fracassar na escola.

A discussão e análise dos depoimentos colhidos nesta investigação possibilitaram-nos chegar a quatro categorias de respostas elencadas pelos entrevistados para conceituar fracasso escolar:

Tabela 01: Conceituando fracasso escolar

\section{Não prestar atenção}

\footnotetext{
${ }^{1}$ A frase foi adaptada ao sexo e idade de cada participante entrevistado. 


\begin{tabular}{|c|c|c|c|c|c|c|c|c|c|}
\hline \multicolumn{2}{|c|}{ Reprovar } & \multicolumn{2}{|c|}{$\begin{array}{c}\text { Tirar notas } \\
\text { baixas } \\
\text { Não aprender }\end{array}$} & \multicolumn{2}{|c|}{$\begin{array}{c}\text { Ser mau aluno } \\
\text { Não levar os estudos a } \\
\text { sério }\end{array}$} & \multicolumn{2}{|c|}{$\begin{array}{c}\text { Fatores pessoais e } \\
\text { conjunturais }\end{array}$} & \multicolumn{2}{|c|}{ Total } \\
\hline M & $\mathbf{F}$ & M & $\mathbf{F}$ & M & $\mathbf{F}$ & $\mathbf{M}$ & $\mathbf{F}$ & $\mathbf{M}$ & $\mathbf{F}$ \\
\hline 08 & 06 & 03 & 09 & 05 & 10 & - & 08 & 16 & 33 \\
\hline
\end{tabular}

Fonte: Entrevistas e diário de campo.

A tabela 01 apresenta as respostas e os respectivos conceitos para o fracasso escolar. Um total de 14 alunos conceituam fracasso associando-o à reprovação. Em suas respostas, pode-se perceber claramente a forte presença da cultura da reprovação produzida historicamente pela escola (RIBEIRO, 1991).

Conforme Jacomini (2010), a crença no poder pedagógico da reprovação e a aceitação de que as causas do não aprendizado residem na falta de interesse dos alunos ainda é dominante e fortemente disseminada na sociedade como ideologia, o que está presente no conceito de fracasso eleito por esse grupo de adolescentes.

Um segundo grupo de 12 alunos conceitua o fracasso a partir do âmbito das baixas expectativas e baixo rendimento. Nas entrevistas desse grupo encontramos explicações que nos fazem refletir sobre o papel da avaliação e sua relação com o fracasso escolar. A sociedade busca cada vez mais o êxito profissional, a competência a qualquer custo, e a escola também segue essa atitude. Aqueles que não conseguem responder às exigências da instituição sofrem e a busca incansável e imediata pela perfeição leva à rotulação daqueles que não se encaixam nos parâmetros impostos.

As entrevistas que voltam a compreensão das questões relacionadas ao fenômeno do fracasso escolar para o próprio sujeito são discutidas por um grupo de 15 alunos, que usaram, em suas respostas, expressões como "não prestar atenção", "ser mau aluno", "não levar os estudos a sério", "não fazer nada" ou mesmo "fazer algo errado". Problemas de comportamento, indisciplina, falta de interesse, entre outros, têm sido apontados como causas do fracasso, uma concepção cristalizada no discurso escolar que parece ter sido incorporada por nossos entrevistados.

Outra faceta da culpabilização da própria vítima está presente nas falas dos adolescentes ao se referirem aos alunos que "brincam" e não cumprem o determinado pela escola. Ao analisarmos as concepções desse grupo, nos remetemos à discussão bastante controversa e atual no cenário educacional brasileiro sobre a indisciplina na escola. La Taille (1996, p.19) discute a indisciplina em sala de aula e sua relação com a moral. Para o autor, “[...] toda moral pede disciplina, mas toda disciplina não é moral [...]”; de fato, certos atos de indisciplina podem ser genuinamente morais. 
Entretanto, no conceito de fracasso escolar apresentado por nossos entrevistados, encontramos elementos para acreditar que a indisciplina é entendida como o simples "não seguir as regras da escola". Trata-se, portanto, do aluno que não faz as atividades, que não obedece aos professores, que "dá trabalho":

Uma pessoa que, por exemplo, pode ser aquele aluno nota dez, que sempre tira boas notas, que de uma hora pra outra começa a decepcionar os professores. E aquela pessoa é uma aluna exemplar e começa a matar aula e não participar. É decepcionante (Alice ${ }^{2}, 14$ anos).

À expressão "aluno nota dez" está associada o "fazer os deveres", "tirar boas notas", "não fazer bagunça", etc. O oposto seria o mau aluno. Ao refletir sobre essa expressão a partir das evocações feitas por Alice, verificamos que seus elementos centrais correspondem aos valores cultuados tradicionalmente pela escola, ou seja, ser aluno nota dez é ser estudioso, inteligente, esforçado, responsável e, essencialmente, submisso às normas escolares préestabelecidas, obtendo boas notas e, invariavelmente, passando de ano. $\mathrm{O}$ bom aluno é, assim, definido, sobretudo, por sua relação de obediência para com as regras da escola.

Contudo, esse quadro não é absoluto, e isso significa um alento para acreditarmos que, em algum momento, o processo educacional contribuiu para a formação ética desses sujeitos ou, pelo menos, das oito meninas que voltam suas explicações não para este ou aquele fator isolado, mas para um conjunto de questões, tanto internas quanto externas à escola. A essa categoria de resposta chamamos de "fatores pessoais e conjunturais".

Nas entrevistas encontramos elementos que nos levam a refletir sobre a importância social da escola, onde os relacionamentos interferem na queixa escolar:

\begin{abstract}
$\mathrm{Ah}$, tem vários tipos de fracassado. Tem aquelas que fracassam porque [sic] quer e aquela porque não tem condições mesmo de melhorar, entendeu? Eu acho que primeiro a gente não deve ligar para o que os outros falam. E se essa pessoa fracassa, tem gente que fracassa porque os pais não têm condições de dar um estudo bom [...] e tem outras que já [sic] fracassa porque quer e fica brincando na hora da aula e fica conversando com as amiga, ou sei lá (Bia, 14 anos).
\end{abstract}

Embora Bia perceba que o fracasso tem várias facetas e que diversas são as questões ligadas a essa problemática, suas possíveis explicações continuam centradas no próprio sujeito e/ou na família. Percebe-se a cristalização das formas de pensar o fracasso como problema dos alunos e/ou nos alunos.

\footnotetext{
${ }^{2}$ Nomes fictícios foram adotados para preservar a identidade dos sujeitos.
} 
A escola é um espaço de interação social. Para muitos desses adolescentes, o vínculo estabelecido entre os colegas, os laços de amizade e os relacionamentos amorosos assumem tal importância que a ausência deles ou a dificuldade em estabelecer essas relações é entendida como fracasso.

Do ponto de vista da teoria piagetiana, esse grupo de oito adolescentes assume uma postura que está de acordo com o previsto no esquema das operações formais, uma vez que o outro passa a ser relevante na compreensão de mundo. $O$ indivíduo que atinge o nível do pensamento formal, no que se refere ao desenvolvimento cognitivo, tem capacidade de contemplar o possível, admitindo suposições, coordenando pontos de vista, argumentando, expressando-se e trabalhando com proposições.

Com base nos dados analisados, não podemos afirmar que as entrevistas revelem diferenças significativas na forma de conceituar fracasso escolar entre meninos e meninas. Há, no entanto, que se dar destaque ao grupo das oito meninas que demonstram pensar o fracasso escolar recorrendo a fatores mais subjetivos.

\subsection{O que sente o aluno que fracassa?}

Discutidos os conceitos de fracasso escolar formulados por nossos entrevistados, cabenos agora pensar sobre o que sente o aluno. Quais os sentimentos que as experiências de fracasso escolar produzem? Quais representações deixadas pela memória do fracasso?

As respostas sobre o sentimento envolvido em tal situação possibilitou-nos a elaboração de 04 categorias de análise, conforme tabela a seguir:

Tabela 02: O sentimento envolvido

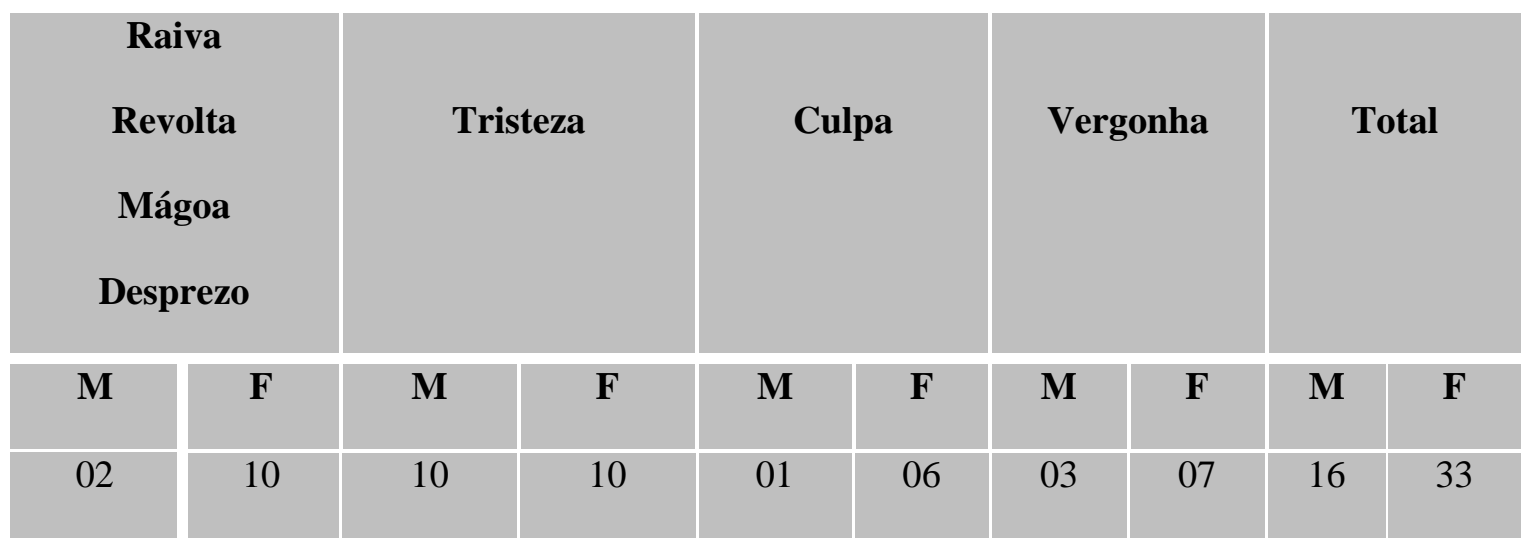

Fonte: Entrevistas e diário de campo.

Para Lewis (1992) e La Taille (2002), simpatia, amore compaixão são sentimentos que levam ao agir moral conforme o dever. A culpa, a vergonha, o embaraço e o orgulho são decorrentes de uma transgressão moral e envolvem uma consciência de si. Por outro lado, 
sentimentos como alegria, tristeza, raiva, surpresa, medo e desgosto são identificados por Lewis (1992) como emoções primárias, por não solicitarem introspecção ou autorreferência. As respostas que envolvem sentimentos como raiva, desprezo, mágoa e tristeza, segundo Lewis (1992), podem ser classificados como não morais. Já as que apresentam sentimentos como culpa e vergonha fazem menção a sentimentos classificados como morais.

Trataremos, de início, dos sentimentos que entendemos como não morais. A baixa autoestima e sentimentos como raiva e tristeza são experimentados por quem sofre o fracasso escolar. Nessa categoria estão incluídas as respostas que relacionam tais sentimentos ao fracassar na escola.

Nesse discurso está presente a concepção de que a maioria das famílias não atribui importância à escolarização dos filhos. A falta de interesse, incentivo e acompanhamento dos pais ao trabalho escolar dos filhos, bem como a indiferença em relação a ações que a escola propõe para solucionar o problema, são mencionados pela escola em pesquisas anteriores (QUEIROZ; ZIBETTI, 2009). No entanto, é sabido que a família não só atribui importância, como pontuam Moysés (2001) e Justo (2006), como também sofre com o fracasso.

Estão arraigadas, no ideário dos atores escolares, explicações deterministas do fracasso escolar, visto como um fenômeno que ocorre por culpa, incompetência ou desinteresse do aluno e da família. No conceito de fracasso escolar apresentado por nossos entrevistados, pode-se perceber que esse movimento de culpabilização do aluno pelo baixo rendimento não advém apenas dos professores, diretores e demais funcionários da escola, mas dos próprios alunos que reproduzem esse discurso cristalizado.

Embora tenhamos classificado tais sentimentos como não morais, compreendemos que toda situação da escola é uma questão ética e moral. Os históricos processos de segregação, discriminação, culpabilização dos alunos e famílias (MACHADO, 1997; PATTO, 2005; SOUZA, 1997) apontam, a nosso ver, para a necessidade de rediscutir a escola em seus valores, sua ética e sua moral, uma vez que "[...] a escola não pode silenciar sobre a educação moral" (LA TAILLE, 2009a p. 273).

Culpa, humilhação e vergonha são geralmente descritos como sentimentos relacionados ao desenvolvimento moral indicando compreensão e internalização de padrões sociais e responsabilidade pessoal (ARAÚJO, 1999; LA TAILLE, 2002). Um grupo de 07 adolescentes faz menção ao sentimento de culpa como decorrente da situação de fracasso. A culpa é geralmente definida como um estado emocional produzido pelo conhecimento que o indivíduo tem após violar regras morais (LA TAILLE, 2006).

O autor esclarece que expressões como "ser culpado" e "sentir culpa" não têm o mesmo significado. $\mathrm{O}$ sujeito pode ser culpado de determinado ato, mas não sentir-se culpado por ele. Em todo caso, os "acusados" podem discordar de tal atribuição. E, por mais que se reconheçam como responsáveis por uma ou outra situação, não sentirão necessariamente culpa por ela: "Para sentir culpa é preciso não apenas reconhecer-se como autor de uma 
determinada ação (intencional ou não) como sentir-se mal por tê-la realizado" (LA TAILLE, 2002, p.135).

A culpa é geralmente sentida por quem, de alguma forma, cometeu um ato de violência contra outrem. Portanto, tal sentimento aparece no contexto de uma relação social. Não parece ser esse o caso de nossos 07 entrevistados, que aparentam sentir outro tipo de culpa, denominada "residual".

Conforme Rawls (1971), a culpa residual está relacionada ao fracasso diante de uma empreitada exclusivamente individual. Nesse caso, o fracassar na escola pode resultar no sentimento de "culpa de não ter prestado mais atenção, se esforçado mais, se dedicado aos estudos”. Segundo Rawls (1971), não se trata de um genuíno sentimento de culpa, uma vez que a pessoa não vai se desculpar perante quem quer que seja. $\mathrm{O}$ verdadeiro sentimento de culpa está relacionado ao que se faz a outrem.

Ao falar em culpa, invariavelmente falamos da vergonha, sentimento mencionado por 10 adolescentes. A vergonha geralmente é vista como um sentimento atrelado à culpa. Contudo, alguns estudos têm demonstrado que, ainda que muitas vezes possam se manifestar juntos, são sentimentos de natureza distinta e não podem ser confundidos (ARAUJO, 1999; LA TAILLE, 2002; HARKOT-DE-LA-TAILLE, 1996).

A culpa ocorre quando o indivíduo avalia negativamente seu comportamento. Nossos entrevistados sentem culpa “[...] por não ter[em] estudado, por não ter[em] se dedicado", mas o sujeito pode se ver livre desse sentimento, se realizar uma ação que repare a ação negativa. Já a vergonha não é produzida por nenhum evento específico, mas pela interpretação que o indivíduo faz de uma situação. Por isso, uma vez que o sujeito sente vergonha, não é possível reverter o sentimento.

Ambos os sentimentos dependem da interiorização de valores que podem levar o sujeito a pensar sobre si. Enquanto a culpa pode levar à reflexão sobre as ações, a vergonha leva o envergonhado a repensar sua própria identidade:

Vergonha. Porque acho que, no caso, se eu fracassasse ficaria envergonhada das pessoas que estão ao meu redor, porque iriam pensar assim: "poxa uma menina tão estudiosa fracassar logo agora" (Paula, 15 anos).

Comparando os relatos sobre vergonha com os sobre culpa, podemos compreender que esse sentimento, a culpa, está associada a alguma forma de transgressão. Já a primeira, sentida por Paula, relaciona-se com um ideal que não foi mantido ou atingido. Nesse sentido, concordamos com La Taille (2002, p.144, grifos do autor) quando afirma que "[...] a culpa é da ordem da transgressão e a vergonha da ordem do fracasso." de não manter ou alcançar uma "boa imagem". Sente-se culpa pelo que se fez e vergonha, do que se é. 
Aqui recorremos novamente à La Taille (2002), ao falar do espaço ocupado por tais sentimentos. Na culpa a relação é privada, no sentido de que somente pode ser sentida em relação às pessoas com as quais estabelecemos algum tipo de relação. Já a vergonha ocupa um espaço mais público, uma vez que pode ser sentida em relação a todas as pessoas da comunidade moral na qual estamos inseridos.

Os dados obtidos nos levam a refletir sobre o espaço ocupado pelos sentimentos morais. Para nossos entrevistados, sentimentos não morais como a raiva e a tristeza têm maior apelo do que aqueles morais. Parece-nos que o respeito pelo espaço público não é tão relevante quanto pelo privado. $\mathrm{O}$ fracassar na escola é sentido, mas não como fracasso na vida. Em pesquisa sobre os valores dos jovens de São Paulo, La Taille e Harkot-de-La-Taille (2006) chamam atenção para essa tendência do jovem de se desertar do espaço público e recolher-se ao espaço privado.

Conforme Piaget (1994), por volta dos 12 anos de idade, o sujeito passa a conceber a si mesmo como possível agente do universo moral, capaz de estabelecer e defender regras e pensar com autonomia. Com base nisso, esperava-se que nossos entrevistados, em sua maioria com idade entre os 14 e 15 anos, estivessem nessa condição, elegendo sentimentos morais diante da situação de fracasso, mas tal não ocorreu.

É na adolescência que se dá, no processo de desenvolvimento moral, a aquisição de valores como a justiça distributiva e a equidade. Para o autor, o adolescente encontra-se na fase de conquista da autonomia moral, em que pode construir juízos independentes, não aceitando valores interiorizados a partir da coação adulta.

Nossa hipótese era a de que os adolescentes compreendessem que a responsabilidade pelo fracasso não está exclusivamente no sujeito, mas que as condições externas exercem influências, e tenderiam a apresentar representações positivas de si e/ou de outrem. E, em contrapartida, os sujeitos que apresentassem uma representação negativa de si e/ou de outrem procurariam responsabilizar o próprio sujeito pelo fracasso e teriam a vergonha como o sentimento experimentado pelo indivíduo.

Quando tratamos do sentimento experimentado por quem fracassa na escola, percebemos que sentimentos não morais como a raiva e a tristeza têm maior apelo do que aqueles considerados morais, como culpa e vergonha. Acreditamos que tal aspecto evidencia que o respeito pelo espaço público não é tão relevante quanto pelo privado.

La Taille e Harkot-de-La-Taille (2006) discutem que instituições públicas como a mídia, a religião, os partidos políticos, dentre outras, são consideradas pouco merecedoras de confiança por parte dos jovens. Em contrapartida, há uma clara valorização da família, das relações de amizade, enfim, do espaço privado em detrimento do público.

Para esses autores, tais dados são relevantes para a compreensão da dimensão moral em nossa sociedade, uma vez que atribuir valor e confiança apenas à esfera privada não somente reduz drasticamente o número de pessoas a quem se atribui senso moral, como 
equivale a uma constatação de pouco exercício da cidadania, característica desejável nas ações do espaço público.

Quanto aos nossos sujeitos, não podemos afirmar que não sentem vergonha ou não compreendem as regras ou não as validem, pois nossos dados os comprovam. Precisamos, entretanto, abordar, nesta discussão, como esse sentimento e a validação da moralidade estão inseridos na representação de si. Nessa perspectiva, acreditamos que nossos dados apontaram para o fato de que é relevante compreender o espaço para sentir vergonha.

Sobre a dicotomia entre público vs. privado, Sennett (2002) comenta que a celebração indiscriminada do culto à intimidade pode conduzir a tal hipertrofia da esfera íntima que, no limite, chegaria a implicar um retraimento do espaço público, por meio do afrouxamento dos papéis sociais que o constituem.

Ora, se as relações no espaço privado estão cada vez mais valorizadas, o fracasso não é sentido como um fracasso na vida, mas apenas como um fracasso temporário; não sendo, nesse caso, motivo para se envergonhar ou sentir culpa. Se não fizeram a outrem, mas a si mesmos, é possível "consertar" e, logo, não há motivo para vergonha.

Tais dados nos inquietam, pois questionam postulações teóricas críveis nas áreas da psicologia moral e da psicologia escolar até então. No que diz respeito à psicologia moral (LA TAILLE, 2002, 2009b), acredita-se que o sujeito, diante de uma situação pela qual se sente responsável, culpado, sente vergonha e esse sentimento implica numa representação negativa de si mesmo diante de seu grupo, considerando que esse sujeito já está desenvolvido moralmente no que diz respeito a ser capaz de questionar e validar a moralidade de seu grupo.

No que diz respeito à psicologia escolar (SOUZA, 2004; COLLARES, MOYSÉS, 1996), os sujeitos, ao fracassarem na escola, comentam que se sentem fracassados para a vida, pois a sociedade, suas famílias e eles próprios ainda enxergam a escola como a forma para progredir na vida e "ser alguém".

Mas nossos sujeitos, já desenvolvidos moralmente, sentem-se culpados pelo fracasso. Questionam suas atitudes diante da escola e, simultaneamente, discutem alguns posicionamentos da escola e de professores - demonstrando sua capacidade de questionamento das regras. Todavia, em alguns casos, não sentem vergonha e, em outros, apesar de a sentirem, isso não caracteriza uma representação negativa de si.

Se encontramos em nossos sujeitos o desenvolvimento moral pertinente ao desenvolvimento cognitivo, não podemos postular que eles não compreendam os efeitos para sua vida futura. Só podemos postular que é uma questão de valores, do que realmente se apresenta como um valor para estes sujeitos, e nos parece que não são aqueles do espaço público, mas os do espaço privado. Caberia aqui discutir o lugar ocupado pelo desempenho escolar no rol de valores admirados por nossos entrevistados. Entretanto, acreditamos que, para tal, outros estudos são necessários. 
Chegamos, então, a duas questões que carecem ser levantadas. Primeira: em nossa sociedade, ainda é válido que, para ser-se moral, deve-se ter como referência o outro? Ou devemos considerar cada vez mais a moralidade também nos aspectos relacionados a si? Infelizmente, esta pesquisa não tem dados para responder a contento, mas acreditamos que os resultados obtidos apontem para a necessidade de se ampliar a discussão.

Segunda: será que a escola está deixando de ser considerada relevante para a vida dos indivíduos? Apesar de concordarmos com Justo (2006, p.35), quando afirma que a escola continua sendo "[...] grande sustentáculo da sociedade e considerada como elemento-chave da formação do sujeito, da construção da cidadania [...]”, os dados indicam-nos que, para os entrevistados, a escola não tem a relevância que teve em nossas vidas e na de muitos que conhecemos. Novamente, apontamos a necessidade de pesquisas que ampliem essa discussão.

Nossos entrevistados parecem julgar-se negativamente diante do fracasso escolar, mas apenas diante de um momento específico e em função de uma situação em particular, e isso vale mesmo para situações que não dizem respeito a experiências particulares, mas servem também para quando se imaginam fracassando, ou quando falam da experiência de outrem.

O sentimento de vergonha comparece, mas não implica que ele se represente negativamente. Acreditamos, portanto, que se trate aqui de uma questão do status diante dos colegas da escola naquele momento. Há, na verdade, uma vergonha do julgamento do outro, mas que não parece representar um julgamento negativo de si próprio.

A nosso ver, esses sujeitos continuam cultivando o sentimento de vergonha, porém a comungam com os fracassos pessoais, conforme pontua Vitale (1994, p.167), afirmando que "[...] a vergonha perdeu seu caráter de sentimento moral no trato das questões do espaço público [...]". Isto é, as pessoas permanecem sentindo vergonha, mas associam-na a seus fracassos pessoais e demais decepções individualistas.

Os dados endossam a ideia de La Taille (2002, p.65) de que "[...] a busca de representações positivas é uma das motivações básicas das condutas humanas.”, pois analisando o que sentem os entrevistados diante do fracasso escolar, bem como os aspectos relevantes e significativos das representações que fazem de si, podemos dizer, ainda que com certa cautela, que os participantes de nosso estudo não se sentem fracassados e, embora a maioria atribua a culpa do fracasso a si mesma, representa-se positivamente.

\section{Palavras finais}

Partindo de um tema clássico como a moral, em interface com a polêmica discussão do fracasso escolar, o presente texto buscou compreender como a representação de si 
relaciona-se com o sentimento de vergonha e a experiência de fracasso escolar, de si e/ou de outrem.

Por meio de suas experiências e interações, os sujeitos vão construindo saberes que lhes permitem atribuir sentido a conceitos materiais ou abstratos. Na escola, circulam múltiplos significados que são percebidos de diferentes formas por seus atores por meio dos quais cada um constrói o sentido pessoal de suas vivências escolares. Assim, a escola pode ser considerada tanto como um espaço de possibilidades prazerosas, quanto um espaço repressor e sem alegria.

Os dados nos levam a refletir sobre o espaço ocupado pelos sentimentos morais. Para nossos entrevistados, sentimentos não morais como a raiva e a tristeza têm maior apelo do que aqueles morais. Nossos entrevistados parecem julgar-se negativamente diante do fracasso escolar, mas apenas diante de um momento específico e em função de uma situação em particular. O sentimento de vergonha comparece, mas não implica em representação de si negativa.

Nossos dados parecem endossar a ideia de La Taille (2002), segundo a qual a busca de representações positivas é uma das motivações básicas das condutas humanas. Dessa forma, analisando o que sentem os sujeitos diante do fracasso escolar, bem como os aspectos relevantes e significativos das representações que fazem de si, podemos dizer que os alunos entrevistados não se sentem fracassados e, embora a maioria deles atribua a culpa do fracasso a si mesmos, representam-se positivamente.

Em relação ao fracasso escolar, consideramos que não basta encontrar as causas e as soluções: é necessário intensificar a vigilância sobre os efeitos das políticas públicas na vida dos alunos; é preciso avivar a compreensão das relações que eles mantêm com a escola; e, principalmente, estimular o respeito ao direito básico de uma educação escolar que não possibilite experiências de fracasso.

\section{Referências}

ARAÚJO, U. F. Conto de escola: a vergonha como um regulador moral. São Paulo: Moderna, 1999.

BOCK, A. M. B. Psicologia da educação: cumplicidade ideológica. In: MEIRA, M. E. M.; ANTUNES, M. A. M. (org.) Psicologia escolar: teorias críticas. São Paulo: Casa do Psicólogo, 2003.

COLlARES, C. A. L.; MOYSÉS, M. A. A. Preconceito no cotidiano escolar: ensino e medicalização. São Paulo: Cortez: Campinas, SP: UNICAMP, 1996. 
HARKOT-DE-LA-TAILLE, E. Ensaio semiótico sobre a vergonha. Tese (Doutorado em semiótica e linguística geral) - Faculdade de Filosofia, Letras e Ciências Humanas, Universidade de São Paulo, 1996.

Ensaio semiótico sobre a vergonha. São Paulo: Humanitas, 1999.

JACOMINI, M. A. Educar sem reprovar. São Paulo: Cortez, 2010.

JUSTO, J. S. Escola no epicentro da crise social. In: LA TAILLE, Y. Indisciplina/disciplina: ética, moral e ação do professor. Porto Alegre: Mediação, 2006.

LA TAILLE, Y. As virtudes segundo os jovens. In: LA TAILLE, Y.; MENIN, M. S. S. (org.). Crise de Valores ou Valores em Crise? Porto Alegre: ArtMed, 2009a.

Y. Formação ética: do tédio ao respeito de si. Porto Alegre, Artmed, $2009 \mathrm{~b}$.

Y. Vergonha: a ferida moral. Petrópolis: Vozes, 2002.

Y. Desenvolvimento humano: contribuições da psicologia moral. Psicologia USP. São Paulo, v. 18, n. 1, p. 11-36, 2007.

Y. A indisciplina e o sentimento de vergonha. In: AQUINO, J. G. (org.) Indisciplina na escola: alternativas teóricas e práticas. São Paulo: Summus, 1996.

Y. Moral e ética: uma leitura psicológica. Psicologia: Teoria e pesquisa. Brasília, v. 26, n. especial, p. 105-114, 2010.

Y.; HARKOT-DE-LA-TAILLE, E. Valores dos jovens de São Paulo. In: LA TAILLE, Y. Moral e ética: dimensões intelectuais e afetivas (apêndice). Porto Alegre: Artmed, 2006.

LEWIS, M. Shame- the exposed self. New York: The Free Pass, 1992.

MACHADO, A. M. Avaliação e fracasso: a produção coletiva da queixa escolar. In:

AQUINO, J.G. (org.) Erro e fracasso na escola: Alternativas Teóricas e Práticas. São Paulo: Cortez, 1997.

MOYSÉS, M. A. A. A Institucionalização invisível: Crianças que não-aprendem-na-escola. Campinas, SP: Mercado das Letras; São Paulo: FAPESP, 2001.

PATTO, M. H. S. Exercícios de indignação: escritos de educação e Psicologia. São Paulo: Casa do Psicólogo, 2005.

PIAGET, J. O juízo moral na criança. 4. ed. São Paulo: Summus, 1994. 
QUEIROZ, K. J. M.; ZIBETTI, M. L. T. Os desafios da alfabetização: O que pensam as professoras alfabetizadoras? Caderno de Pesquisa e Criação. Universidade Federal de Rondônia. Porto Velho, 2009.

K. J. M.; LIMA, V. A. A. Método Clínico piagetiano nos estudos sobre Psicologia Moral: o uso de dilemas. Schème: Revista Eletrônica de Psicologia e Epistemologia Genéticas, v. 3, p. 110-131, 2011.

RAWLS, J. Théorie de la justice. Paris: Seuil, 1971.

RIBEIRO, S. C. A pedagogia da repetência. In: Estudos em Avaliação Educacional, São Paulo, n. 4, jan./dez., 1991.

SANNETT, R. O declínio do homem público: as tiranias da intimidade. São Paulo: Companhia das Letras, 2002.

SOUZA, M. P. R.; MACHADO, A. M. As crianças excluídas da escola: um alerta para a Psicologia. In: MACHADO, A. M.; SOUZA, M. P. R. (org.). Psicologia escolar: em busca de novos rumos. São Paulo: Casa do Psicólogo, 2004.

M. P. R. As crianças excluídas da escola: um alerta para a Psicologia. In:

MACHADO, A. M. e SOUZA, M.P.R. (org.). Psicologia Escolar: em busca de novos rumos. São Paulo: Casa do Psicólogo, 1997.

VITALE, M. A. F. Vergonha: um estudo em três gerações. 1994. 191f. Tese (Doutorado) Pontifícia Universidade Católica de São Paulo, São Paulo, 1994.

Recebido em: 17/12/2014

Revisado em: 26/10/2015

Aprovado para publicação em: 18/11/2015

Publicado em: 31/08/2016 